\title{
Constructivism Representatives about Cognition Process
}

\author{
Naira Danielyan \\ National Research University of Electronic Technology
}

\begin{abstract}
The article provides an analysis of the approach to cognition in the theory of constructivism according to different constructivism concepts such as: methodical constructivism, scientific-theoretical constructivism, natural epistemology, personal construct theory, social constructivism, concepts of some radical constructivism representatives, constructive realism. The analysis demonstrates that constructivism helps to establish subject's control over the reality perceived by him when eliminating any deviations or resentments from his preferable target condition. In this case, the model of the world cognized contains only the aspects which are relevant to subject's purposes and actions. It is advanced the idea the current stage of science development is connected with the change of its fundamental bases. As a result, the model of the reality becomes a result of interaction between subject of scientific and cognitive activity with the reality, but the ideas of constructivism in its classical meaning don't correspond to this conclusion. The author proves that cognition based on the constructive realism is the most appropriate to the modern stage of epistemology development as it cancels the opposition of constructivism and realism in some extent and promotes getting a rational knowledge about the reality by subject.
\end{abstract}

Keywords: constructivism, epistemology, cognition, rational knowledge, interpretation, perception

\section{Introduction}

Constructivism ideas are popular nowadays among philosophers and representatives of different humanitarian sciences. Their consideration leads to a number of important methodological results concerning the theory of constructivism, its applicability, and possible conclusions. Mainly, it is connected with the situation that nowadays it's impossible to predict exactly both the future of science and the future of civilization it determines. In this regard, constructivist versions of cognition are in high demand in contemporary philosophical and methodological reflection of science. The reason is that they confirm a lot of intuitive insights of science, and hide a powerful reserve of its future development and unknown possibilities of its structural organization. Moreover, they require the epistemological principles and methods which haven't been known to the philosophical reflection yet.

If to give a short description, epistemological constructivism is an approach that supposes the construction of the surrounding world by man in the limits of his perception and mentality. The presence of outer world is not denied, however, cognition stops to be defined by the statement of its objective existence. It means that subject's mind doesn't process the information received outside any more or decide the specified problem situations.

If to study the process of receiving a reliable knowledge in the constructivism theory, it's possible to

Naira Danielyan, Doctor of Philosophy, Professor of Philosophy, Sociology, and Politology Department, National Research University of Electronic Technology, Russia; main research fields: Philosophy and Epistemology. 
conclude that it is a complex of interconnected ideals and regulative principles by knowledge production and translation which has been formed historically in the scientific community. Following the method of searching thought, the object of a cognition process is a question which the subject of this process hasn't answered yet. Besides, he isn't able to get it from his memory, direct observations, reading textbooks and reference books or asking specialists. While reasoning, subject forms an object field. It's a relatively narrow circle of phenomena concerning the search of an answer to a cognitively significant question directly.

This approach is being developed in the modern philosophical literature on the basis of different disciplinary fields. The most popular and studied theories in philosophic literature are the following: genetic epistemology by J. Piaget (1972; 1974; 1978), cybernetics of cybernetics by H. von Foerster (1996; 1998), communication constructivism by P. Watzlawick (1976; 1981), radical constructivism by E. von Glasersfeld (1996), and concept of autopoietic systems by H. Maturana and F. Varela (1975). Undoubtedly, there are other versions of constructivism. This article tries to reflect the history of appearing and developing the constructivism tendencies including the theories that have been covered in international philosophical literature insufficiently.

\section{From History of Different Constructivism Schools’ Ideas}

\subsection{Methodical Constructivism of Erlangen School}

This direction in philosophical thought appeared as a result of the joint work of two philosophers: Wilhelm Kamlah and Paul Lorenzen (1967) from Erlangen University, Germany in 1962. The two scientists' thematic approach existed from the early 1970s to the late 1980s.

The main feature of methodical constructivism is a search of science foundation: They insist that human consciousness and perception shouldn’t be considered according to R. Descartes and I. Kant. Instead W. Kamlah and P. Lorenzen offered to follow "life chance proved line of behavior" (Gethmann 1994, 749). This fundamental program has been applied to all spheres of logics, mathematics and physics by such scientists as G. Böhme (1976) and J. Pfarr (1981), to ethics and culturology by P. Lorenzen and O. Schwemmer (1975).

Trying to decide the problem of scientific rationality, P. Lorenzen suggested making a difference between science in the context of research which contains the expression of objective rationality and science in the context of description being characterized by rationality of proof. He believed the difference between the context of discovery and the context of proof shouldn't be mixed with the difference between the context of research and the context of description.

Let's describe the general features of methodical constructivism. As a result of discussions concerning the details of the fundamental program realization, it was found out the methodical bases of science should be considered according to the problematic of the issue being under consideration (the details are given in the treatise by H. Albert, 1980). The idea of systematic arrangement of scientific theories seemed to be outdated owing to the critics of empiricism in science perception, i.e., the criticism of this approach by T. Kuhn and P. Feyerabend (Hoyoung Choe 2008, 15). Following this conclusion, the successors of Erlangen School of constructivism reconsidered a priori construction of scientific theory (Stekeler-Weithofer 1995, 12) by means of a prototheory. They tried to apply constructivism principles to the creation of different phenomena in specialized empiric fields relying on the tools used. According to this theory, science should be formed methodically, layer by layer: exact experience in tools creation, then the materials used, after that the methodic 
formation of space and time ideas. Protophysics, protochemistry, protobiology, etc., should be created this way. Thus, the representatives of this constructivism school offered to construct science itself.

\subsection{Scientific-Theoretical Constructivism by K. Holzkamp}

There were a lot of discussions in the German-speaking world in the 1970s connected with the version of constructivism offered by Klaus Holzkamp (1968; 1972). He criticized such directions as "naïve empiricism,” "logic empiricism," up to K. Popper's theory of falsification calling them "the deviation from modern scientific doctrine” (Holzkamp 1972, 80) by means of scientific-theoretical discussions. He found out more and more deviations from the satisfaction of rational requirements to the realization of the cognition theory interests in the above directions.

He suggested the following five theses:

- empirical content and a chance of independent verification are more closely connected with the creation of theoretical scientific language than they point out the level of approaching the reality by the theory being under consideration;

- interpretation of truth as a regulative principle doesn’t stimulate the research process at all;

- conception of approaching the truth by the method of eliminating mistakes is incompatible with K. Popper's methodology or well-founded;

- $\quad$ proper methods to define the validity of a scientific theory exist;

- problem of residual character of the verification theory by K. Popper which is incompatible with the fallible methodology takes place.

Following "the logical superiority of the theoretical" (Holzkamp 1972, 92), K. Holzkamp stressed the importance of "method of examining the options" as the central moment in the scientific work instead of falsification principle by K. Popper. He explained the method of protecting theory from incorrect data by means of external "misrepresented" terms in the scientific theory.

\subsection{Natural Epistemology}

This direction is known well to Russian epistemologists and psychologists. Naturalized or natural epistemology is connected with the solution of epistemological issues while using scientific methods and theories, in particular, taken from natural science (e.g., works by J. Maffie 1990), H. Kornblith (1992). Willard Van Orman Quine formulated the bases of this direction. In contrast to the philosophical tradition which we can see in the classic cognition theory, the concept of "naturalized epistemology” by Quine is a branch of natural science, but it has a psychological foundation. The “old” epistemological tradition (before Quine’s concept) tried to involve natural science; it was built on perception. According to Quine,

it studies a natural phenomenon, viz., physical human subject... We are studying how the human subject of our study posits bodies and projects his physics from his data, and we appreciate that our position in the world is just like his. Our every epistemological enterprise, therefore, and the psychology wherein it is a component chapter, and the whole of natural science wherein psychology is a component book—all this is our own construction or projection from stimulations that we have determined for our epistemological subject. (Quine 1969, 82)

That is, a double inclusion takes place: first, epistemology into natural science and, second, natural science into epistemology. 
Nowadays the project of epistemology naturalization considering social and cultural points of view is widespread (Luhmann 1984, 1988; Kornblith 1992). It examines the correlation between natural scientific and social scientific aspects of cognition as opposite (Wartofsky 1987) or accompanying (Campbell 1988).

Searching answers on epistemological issues with the application of scientific methods and theories often involves the problem of circulation. These methods and theories should be capable to analyze suppositions and hypotheses and substantiate them. They should also use approaches of transcendental and metaphysical epistemology. The disciplinary differentiation between philosophy and empiric sciences lies in such opposites as fact/importance, descriptive/normative, synthetic/analytic, empiric/transcendental. The role of "naturalized epistemology” is in their unification as a whole, according to Quine.

\subsection{Radical Constructivism}

There is a critical problematic shift considered in works of radical constructivism representatives in comparison with the directions examined the above. Their works aren't devoted to the methods of construction of scientific theories or their language as it was in methodical and scientific-theoretical constructivism. They don’t study the possibility of including epistemology into natural science as natural epistemology does. They research the construction of the reality by subject in the process of cognition. That's why the central position in radical constructivists' works belongs to the research how subject creates a construction which becomes the reality he deals with. Two main peculiarities can be noticed in them: critical attitude to realism and orientation onto modern theory of self-organization. As the theories of communication constructivism by P. Watzlawick, genetic epistemology by J. Piaget, and radical constructivism by E. von Glasersfeld have already been analyzed a lot and well-known to the Russian philosophical society, I'd like to describe shortly the main ideas of cybernetics of cybernetics by H. von Foerster, concept of autopoietic systems by H. Maturana and F. Varela, and the "second-order observation" theory by $\mathrm{N}$. Luhmann as they are absolutely necessary to make conclusions at the end of the article which would disclose substantially new features and forms of rationality.

\subsubsection{Cybernetics of Cybernetics by H. von Foerster}

H. von Foerster claims in his "cybernatics of cybernatics" that there is always the idea of cyclicity in self-organization of any system as it is the process of organization of some organization. He paid attention to "circularity" of phenomena which takes place in cybernatics by means of positive and negative feedbacks of system elements. When such a circulation takes place, causa efficientis (initial reason) and causa finalis (final reason) by Aristotle should be understood as a single whole (Foerster 1985, 66). Instead of "first-order cybernatics," there appeared "second-order cybernatics" that suggested the transformation from cybernatics of observing systems to cybernatics of observed ones. It meant that observer would tend to "post-objectivity" discovering his features instead of objectivity which didn't take his peculiarities into account. Foerster proves that everything what can be said is said by observer in "second-order cybernatics." So, any observation is impossible without observer. This conclusion means that observer (a man) doesn't reflect the world in such an extent as constructs it. Thus, he can't learn the reality. Every observer will construct his own reality and try to learn his own world. In fact, he is alone from epistemological point of view as he observes and constructs the surrounding world on the strength of his cognition abilities and possibilities. One observer's truth will be wrong for another one. As a result, the cognition process gets a cyclic character and the purpose of cognition will be in cognition itself. On the basis of the above, it's possible to conclude that the synergy conception is explained differently in compassion with the theory of "second-order cybernatics." 


\subsubsection{Concept of Autopoietic Systems}

The autopoiesis concept by H. Maturana and F. Varela has an orientation on the research of systems which are closed operationally and can self-reproduce themselves. That's why human brain is considered by them as a system producing the world insulated cognitively. They offer to learn "living systems as a process taking place in the reality, but not to interpret them through the connection with the reality” (Maturana and Varela 1987, 9). Neither living system can be identified separately from its environment. However, the environment can initiate some structural changes of an organism, but can't specify them. According to the theory of the autopoiesis, nervous system is involved in inner cycles of life support. It doesn't have any target in its surrounding as the target is inside the system itself. Hence, a man as "a living system” doesn't just reflect the world surrounding him, but constructs it in correspondence with his cognitive, existential, and social sets. As an autopoietic system, a man progresses independently while broadening his relations with the world. It leads to the appearance of inner and outer relations which form his personal space.

The principle of operational "insularity” doesn't mean “closedness” at all. It should be considered as conceding autonomy of living systems, their interaction with the environment and self-development. Self-regulated systems don't control "exit,” but "entrance.” They function due to the feedback principle. The theory of constructivism suggests that "entrance" doesn't correspond to the results an outer observer can get. It will be a result of system's perception. This idea explains why living bodies stay stable to the outer impact in spite of their regular contact with the environment. It leads us to the thought that autopoietic systems renew themselves, that's why they are the only product of their organization. Their own organization stays invariant, i.e., it specifies a net of their interactions. However, any living body goes through some changes occurring together with the environmental ones. Neither living system can be defined separately from its environment which initiates, but doesn't specify this system's structural changes.

Thus, autopoietic systems have the following features:

(1) operational insularity—self-organization process is possible due to the feedback based on system's inner laws. It's not guided from outside;

(2) informational insularity—any "outer" influence should be transformed in "inner" state of brain activity, because such a system can respond only to them;

(3) physical openness - there is an exchange of substances and energy with the environment and its character is defined by autopoietic system.

It's possible to note that constructivism epistemology runs through the autopoiesis concept of living systems as cognitive ones. System's inner state forms subject's idea of the environment. However, there is always an outer observer who could play a role of subject observed in his turn. This process of changing observers is limitless in fact as there cannot be "the last observer," i.e., some exclusive observation system doesn't exist. It means that absolute objective knowledge about the world cannot be achieved. So, the rationality of cognition will be in the world constructed by an observer and the theory of constructivism could be considered as the theory of observation systems.

It's interesting to note that synergy principles allow us to learn a man as a complex self-organizing object whose epistemological activity occurs in correspondence with logics of synergetic models. It's possible to conclude after studying the cognition process in the theory of radical constructivism that the achievement of some balance between the reality and the result of subject's cognition activity is impossible in practice. As subject constructs the world, everyone will have his own reality. It means that subject doesn't feel any 
“resistance" from the reality. He doesn't see any boundary between his own experience and the reality itself. Application of this idea to the theory of self-organization can lead us to the thought of cognition self-organization by subject (examples can be found in works by P. Watzlawick, J. Piaget). If some knowledge received by subject corresponds to the reality, it means construct's coincidence with the world perceived that can be both subjective and physical. Hence, cognition is adaptation (object has got something similar to subject's activity).

\subsection{3. “Second-Order Observation” by N. Luhmann}

N. Luhmann applied the concept of self-organization to "paradigm alteration in the theory of systems" (Luhmann 1984, 15). He also used it very fruitfully to construct his sociological theory. As a result of this work, he made a conclusion that "the idea to apply a self-referent way of work to the theory of social systems is situated in the center (the way of cyclical organization)” (Luhmann 1997, 11). He also developed constructivism concepts in the epistemology during this work.

His theoretical reflection led to the appearance of "the second-order observation" theory. Luhmann said that "our look catches both sides of one object simultaneously" (Luhmann 1992, 99). The concept of observation is very abstract for him. As a result, there arises a question if this observation "belongs to a man or a machine, brain, consciousness, or a system of communication” (Luhmann and Schorr 1990, 12). At the same time, a question about "differences in observers' equipment status" is excluded (Luhmann and Schorr 1990, 13). He explains "differentiating and marking" observers as a way to use general mechanisms of "surplus production and selection" or "destabilization and suppression" which are connected with the evolution of self-organizing system (Luhmann 1992, 81).

Thus, an observation can have a character of a very complex system. Cells, organisms, societies, systems of artificial intellect are able to play observers' role. The second-order observation or observation of observation is different because of the circumstances of its observation, if an observer himself has performed it or someone or something has been looking after him. According to Luhmann's theory, observer cannot see himself, i.e., he isn't able to make out himself and his observation. At the same time, another observer can see him. He has an ability to see the observer and what is being observed. Luhmann defines this process as the second-order observation (autoreflection idea). According to him, these conditions lie in the foundation of epistemology.

Luhmann tries to avoid that typical hierarchy that is often used in reflection when it's necessary, e.g., to make a difference between object's plane and metaplane or between the transcendental and the empiric. It leads to exclusion of any further observations. The idea of "observation" allows us to avoid the epistemological traditional terminology, in particular, subject-object scheme. For example, it’s possible to consider relationships between a system and its environment while observing. Hence, Luhmann's theory corresponds to the ideas of radical constructivism representatives. According to it, a system cannot exceed its limits and is involved only in its own definitions. "Countless own systems operate inside a man as a condition of his life. They define the operations they implement by means of their own structures despite they're dependent on each other" (Luhmann 1988, 11). It gives an idea that the world of observation is created the same way as any other system activities.

So, an answer on the ontological questions: "What is it?” and "how is it?" will depend on a definite observer restricted by the world of his observation. We can say he is similar to some empiric value that stipulates selecting him as an object by other observers. This constructivism concept looks like more 
sociological than philosophical. The author makes a conclusion that man constructs a society not accidentally, according to his desires, but in co-evolution with the general development of social structure. This process can be explained by human mental abilities to distribute and recombine a structure in general that is necessary while describing differentiated functional systems of the modern society. It is obvious that subject and the environment which he acts in are interconnected constructively and they go through mutual formation in the process of his activity.

The above analysis demonstrates that Luhmann's ideas are rather abstract. He substitutes many concepts accepted generally and created by conceptual frames of human thinking. For example, this remark could be applied to Luhmann's replacement of realistic epistemology by constructivism as a result of replacing the traditional epistemology by "the theory of observations." Thus, observation in his concept is something more than just perception. It is a type of system operations. In this case, describing the world will be a constituent part of the reality, one of its systems.

\subsection{Personal Construct Theory by G. Kelly}

G. Kelly put the foundation of the personal construct theory using a number of philosophical approaches. This theory is known as "constructive alternativism." In comparison with psychoanalysis and behaviorism, it interprets a man as a scientist ("man-scientist" is used on the analogy of "man-biological organism" who reacts passively neither at inner impulses nor at any other circumstances, but he imagines the world by means of his own knowledge, foresees future events and searches the ways to handle them) (Kelly 1955, 4). He believes that man’s organization is much more complex than any "automatic device” (Kelly 1970, 24).

"The Psychology of Personal Constructs" begins with the description of general methodology and the author's philosophical position as assumptions about the world:

(1) existence of the real world and the mankind's gradual approaching to its understanding;

(2) integrity of the world, i.e., functioning as a whole with all its parts;

(3) motion of the world along the time axis, changing towards itself, i.e., the world isn't stable and life changes with time as any matter. The author considers the living thing can be measured in time, can represent other forms of the reality and reflect the reality keeping its own reality at the same time.

Human character doesn't have to conform to strict rational rules, but it should be understood through the evolution of thought:

... our formulation emphasizes the creative capacity of the living thing to represent the environment, not merely to respond to it. Because he can represent his environment, he can place alternative constructions upon it and, indeed, do something about it if it doesn't suit him... Let us give the name constructs to these patterns that are tentatively tried on for size. They are ways of construing the world. They are what enables man, and lower animals too, to chart a course of behavior, explicitly formulated or implicitly acted out, verbally expressed or utterly inarticulate, consistent with other courses of behavior or inconsistent with them, intellectually reasoned or vegetatively sensed. (Kelly 1970, 8)

Thus, the main ideas of "constructive alternativism" are the following: First, man can always interpret the events taking place; second, any event can be interpreted differently and any interpretation process requires proper tools. According to G. Kelly's theory, man looks at the world through transparent patterns trying to adjust them to the reality which forms the world surrounding him. Such adjustment process isn't always successful, but the world turns out to be plain without the patterns offered. G. Kelly calls the patterns "personal constructs” and applies them as a central concept in his theory. They aren’t prints of the world, but definite 
models of the reality constructed in a man's mind. These models allow a man to organize the line of his behavior. They don't always have a word form. There can be nonverbal and unconscious interpretations of the world.

Man is able to predict further development of events using personal constructs like a foundation. The model constructed is checked in the conflict with the reality. It reveals correctness and fallaciousness of the predictions given. If a hypothesis isn't confirmed, the model doesn't function effectively and requires some revision. If personal constructs are used for the prediction of near events, it's rather easy to revise them. However, if they are applied to the prediction of far events, experimental data influence them less, that's why any strict disproof is impossible.

\subsection{Social Constructivism by K. J. Gergen}

K. J. Gergen proclaimed "metatheoretical perspectives" (Gergen 1982) which mean knowledge isn't a reflection of the objective world, but it should be considered as "interchange artifacts" (Gergen 1985b, 266-75). His position is known as social constructivism and has influence psychology most of all. If man uses such a perspective, all things and categories (not only them) should be analyzed from the position of their social construction by psychological science. He provides the following examples: A man tells about social constructions of the person (Gergen 1985a, 3-18), emotions (Harre 1985), memory (Middleton 1990), himself (Grodin 1996), society (Sarbin 1994).

It's an arguable question what social constructivism means and what work social construction implies. K. J. Gergen considers this concept as a modern man's perception of a narrowing range of contemporary human and social types of cognition like systemic disciplines. As a result, he chooses the title "The Social Constructionist Movement in Modern Psychology” for his article in 1985:

(1) What we take to be experience of the world does not in itself dictate the terms by which the world is understood. What we take to be knowledge of the world is not a product of induction, or of the building and testing of general hypotheses.

(2) The terms in which the world is understood are social artifacts, products of historically situated interchanges among people.

(3) The degree to which a given form of understanding prevails or is sustained across time is not fundamentally dependent on the empirical validity of the perspective in question, but on the vicissitudes of social processes (e.g., communication, negotiation, conflict, rhetoric).

(4) Forms of negotiated understanding are of critical significance in social life, as they are integrally connected with many other activities in which people engage. (Gergen 1985b, 266)

It becomes clear from the above that K. J. Gergen's social constructivism is opposed to the interpretation of knowledge as a product of perception and rational thinking of cognoscitive subject which is traditional for constructivism. It is the position that makes Gergen's concept different from the ideas of other constructivism representatives. The author believes people don't construct the world in their individual consciousness, but it is a result of their joint activity, e.g., conversations, different social practices.

Pointing out the importance of the constructivism theories, social constructivism criticizes them for recognizing superiority of one reality "constructs" over others. According to him, everything we consider to be existing, real, valuable, beautiful, correct, worthy of scientific, and spiritual comprehension is constructed by 
means of language in the process of communication with other people. Different world constructions are connected with the perception what exists and what is valuable in different ethnic, professional, scientific, and religious communities. It becomes clear from Gergen's works that the research of this direction is turned to understanding the ways of objective knowledge achievement, studying literary and rhetoric techniques of explanation, describing ideological and value importance of the self-evident, defining a range of changeability of human senses in different cultures. Such kind of research belongs to the group of "qualitative research" which is a modern fast-developing field of methodology of social sciences and psychology (Ulanovsky 2009).

\subsection{Constructive Realism}

According to the research by Ch. Brezna (2010), Austrian politician and philosopher, Friedrich Wallner (1992) can be considered as the founder of constructive realism. His theory is a scientific and cognitive program that finishes constructive understanding of natural sciences and tries to renew a search of sensible life connections by means of interdisciplinary interaction. Although the name "constructive realism" supposes a realistic version, Wallner's position in epistemological and theoretical aspects is constructive one completely. He makes a difference "between the reality as the world behind our cognitive operations, the world which we live in... and the reality as the world which could be obtained only by cognition” (Wallner 1993a, 20). Approach of natural sciences "lies behind ordinary reflection of the reality; it produces relations much more" (Wallner 1993a, 15). According to him, natural sciences don't reflect the world, but give an idea about a number of "microworlds" which are "functional integrities correlated with a specific data set" (Wallner 1993b, 24). Structure of any microworld should satisfy only some definite criteria chosen by scientists.

According to Wallner, a scientist, especially a naturalist, always specializes in a definite field and uses special tools. The main attention isn't paid to circumstances being used to comprehend this field in the interdisciplinary context, but technical opportunities of essential relations helping to answer a raised question. He recognizes an important role of scientific philosophy calling for "the old European idea of educational meaning of science” (Wallner 1993b, 25). In his books, Wallner offers to apply interdisciplinary methods calling them "alienation." A scientist calls for "alienation" if his theory has another structure than the existing methodic potential and is inserted into an absolutely strange context (e.g., physical theory into sociological context). It's possible to conclude from Wallner's theory that a scientist understands constructive and cognitive features in accordance with definite methods and the initial relevant context of natural scientific theory (Wallner 1990, 15).

J. Gibson's research of human perception influenced the formation of the above position in epistemology and social sciences (Gibson 1988). Its importance is in the author's consideration of perception not as a consciousness phenomenon, but as an event of the reality, a necessary component of life. According to him, the sharp opposition of "inner" and "outer" appeared after Descartes disappears. So, cognition together with its constructions begins dealing with the reality.

The analysis of different constructivism concepts in this article demonstrates that the theory of constructive realism removes the confrontation of constructivism and realism. Subject plays an important part in perception constructing it to a certain extent and processing sensor data by definite rules and standards in this theory.

K. Greiner characterizes constructive realism as "an independent scientific-theoretical direction based on the principles of constructivism that includes numerous and obvious epistemological concepts” (Greiner 2005, 
14). The opposition of constructivism and realism is eliminated in constructive realism due to an active role of subject in perception of the reality and its construction in a definite sense.

\section{Conclusions}

After consideration of different constructivism concepts, it is possible to make the following conclusions:

(1) According to methodical constructivism of Erlangen school and scientific-theoretical constructivism by K. Holzkamp, getting a rational knowledge is defined by some algorithm supposed to construct science itself and some methods offered to verify its theory ("method of examining the options" by K. Holzkamp).

(2) The theory of constructivism claims that scientific knowledge should serve to practical purposes. One of the central ideas of "naturalized epistemology" by Quine is the unification of philosophy and natural science by means of the methods offered by him which are based on the construction of the reality exclusively by sense organs independently on the consciousness interpretation results. According to the other concepts considered the above, scientific notions and theories are examined through their vitality, i.e., in structure both mental and sensual balance. It supposes a deviation from the traditional interpretation of the process of getting a rational knowledge, because the transition from knowledge to observation takes place.

(3) It's possible to conclude from the concepts of radical constructivism which have been analyzed that cognition is an active process of subject's constructive activity. First of all, it's the process of constructing the reality perceived by subject by means of his cognitive operations. That's why the knowledge subject gets is a construct of the reality to a greater extent than its reflection. The cognition process and its result (some knowledge) are equal, because subject is able to cognize only the objects he "created" himself.

(4) According to the above constructivism concepts, the cognition process organizes subject's inner world, but it doesn't solve the problem how to describe the objective ontological reality. Since subject constructs perception, the constructs he receives don't necessarily correspond to the ontological world from the position of its reproduction. They can correspond only to the general concept of his experience. If the knowledge received corresponds to the reality, it means the coincidence of the construct with the world perceived by him. Thus, the cognition process is adjustment (object has something similar to subject's actions).

(5) According to radical constructivism, subject is a part of the world he is going to observe $(\mathrm{H}$. von Foerster), some system, an empiric value which will be observed by other observers (N. Luhmann). Thus, every subject has got his own reality, i.e., getting a rational knowledge can't be achieved as the truth is eluded (every subject has got his own truth).

(6) Personal construct theory by G. Kelly and social constructivism by K. J. Gergen allow us to conclude that man interprets the events taking place and any event can be interpreted differently. He looks at the world through "personal patterns" (G. Kelly) or constructs. The activity by their creation can be the process of communication, social practice (K. J. Gergen). Thus, neither knowledge will be the only in its way.

Hence, constructivism helps to establish subject's control over the reality perceived by him when eliminating any deviations or resentments from his preferable target condition. The model of the world cognized will contain only the aspects which are relevant to his purposes and actions. At the same time, subject doesn't take care of the model cognized, but thinks only about compensation of deviations moving on the way to the achievement of his target. It means that subject is able to adjust to changing circumstances.

However, such an approach doesn't correspond to the up-to-date level of science development. Following the concept of constructive realism, it becomes clear that modern scientific model of the reality should be 
considered as a result of the interaction of subject's scientific and cognitive activity with the reality.

V. A. Lektorsky points out that "any construction supposes the reality which it exists in, reveals, and tries to transform. On the other hand, subject reveals and actualizes the reality only through its constructive activity" (Lektorsky 2009, 37). The “constructed” object doesn’t mean a fictitious construct. For example, any piece of furniture surrounding us has been constructed by man and it is a physical reality. All social institutes created by mankind are the reality although they're ideal constructions in a certain sense. If we consider the subjective world of man, it's possible to conclude that, to a large degree, it is also an ideal construct exposed to theoretical and experimental researches. Therefore, the reality could be examined as multilayer and multilevel. Different levels aren't reduced to each other, but there is some dependence among them. Their ways of existence are different, that's why it is allowed to suggest the idea of "different worlds" existence. Each of these "worlds" is real and connected with the others. In such case, subjective world is also the reality, but different from the physical one. So, the adequate cognition process is possible while taking all these components into consideration.

According to V. A. Lektorsky, any border between "inner” (i.e., taking place inside subject of cognition) and "outer" (i.e., its environment) is removed in epistemology nowadays (Lektorsky 2005). This idea means the reality isn't just subject's construction. Nowadays it's supposed that subject of rational and cognitive activities acts on the basis of theoretical schemes and models, methodological rules, empiric information, logic norms of reasoning. They are used as a material to take a decision concerning a mode of action for the current problem. Such a choice from a number of alternatives and a range of possibilities is stipulated by subject's constructive thinking and open for future revision. It's possible to conclude subject isn't a closed system, but supposes openness to the world. Therefore, a scientific model of the reality becomes a result of interaction of subject's activity with the reality. This result corresponds to the theory of constructive realism completely.

In contrast with the classic theory directed to the statement of some fact, the cognition process from the constructive realism's point of view is an act of constructive thinking open for further criticism. Hence, the cognition process is included into the reality, but not excluded from it. It is the aspect in the theory of constructive realism that promotes getting a rational knowledge about the reality by subject.

\section{Works Cited}

Albert, Hans. Treatise about Critical Reasoning. Tübingen: Mohr, 1980.

Böhme, Gernot. Protophysics. Frankfurt am Main: Suhrkamp, 1976.

Brezna, Christa. Theory of Radical Constructivism in NLP Communication Model. Wein: VDM Verlag, 2010.

Campbell, Donald T. “Descriptive Epistemology: Psychological, Sociological and Evolutionary.” Ed. Donald T. Campbell. Methodology and Epistemology for Social Science. Chicago: The University of Chicago Press, 1988. 435-86.

Foerster, Heinz von. Cybernetics of Cybernetics. Minneapolis, Minnesota: Future Systems, 1996.

---. Sight and Insight. Approach to Operational Theory of Cognition. Braunschweig, Wiesbaden: Vieweg, 1985.

Foerster, Heinz von and Pörksen, Bernhard. Truth Is Liars’ Invention: Conversation with Skeptic. Heidelberg: Carl-Auer-Systeme, 1998.

Gergen, Kenneth J. “Social Constructionist Inquiry: Context and Implications.” Eds. Kenneth J. Gergen and Keith E. Davis. The Social Construction of the Person. New York: Springer Verlag, 1985a. 3-18.

---. “The Social Constructionist Movement in Modern Psychology.” American Psychologist 40 (1985b): 266-75.

---. Toward Transformation in Social Knowledge. New York: Springer Verlag, 1982.

Gethmann, Carl Friedrich. “Constructivism Theory.” Ed. Jürgen Mittelstraß. Encyclopedia of Philosophy and Science. Bd. 4. Stuttgart: Metzler Verlag, 1994. 746-58. 
Gibson, James J. Ecological Approach to Visual Perception (Translation into Russian). Moscow: Progress, 1988. Glasersfeld, Ernst von. Radical Constructivism: A Way of Knowing and Learning. London: Falmer Press, 1996.

Greiner, Kurt. Treatment by Science. Wein: Peter Lang Verlag, 2005.

Grodin, Debra and Lindlof, Thomas R. Constructing the Self in a Mediated World. London: Sage, 1996.

Harre, Rom. Varieties of Realism. Oxford: Blackwell, 1985.

Holzkamp, Klaus. Critical Psychology. Frankfurt am Main: Fischer, 1972.

---. Science as Action. Berlin: Walter de Gruyter \& Co., 1968.

Hoyoung Choe. To Moderate Perspective of Constructivism. Berlin: VDM Verlag Dr. Müller, 2008.

Kamlah, Willhelm and Lorenzen, Paul. Logical Preliminary Study or Preschool of Sensible Speeches. Mannheim: Taschenbuch Verlag, 1967.

Kelly, George. “A Brief Introduction to Personal Construct Theory.” Ed. Don Bannister. Perspectives in Personal Construct Theory. London, New York: Academic Press, 1970. 1-29.

---. The Psychology of Personal Constructs, Vol. 1. New York: Norton, 1955.

Kornblith, Hilary. "Naturalized Epistemology.” Eds. Jonathan Dancy and Ernest Sosa. A Companion to Epistemology. Oxford: Blackwell, 1992. 297-300.

Lektorsky, Vyacheslav A. “Kant, Radical Constructivism and Constructive Realism in Epistemology.” Questions of Philosophy 8 (2005): 11-21.

---. "Realism, Antirealism, Constructivism and Constructive Realism in Modern Epistemology and Science.” Ed. Vacheslav A. Lektorsky. Constructive Approach in Epistemology and Sciences of Man. Moscow: Canon+, Reabilitation, 2009. 4-40.

Lorenzen, Paul and Schwemmer, Oswald. Constructive Logics, Ethics and Science Theory. Mannheim: Bibliographisches Institut, 1975.

Luhmann, Niklas. Observation of Modernity. Opladen: Westdeutscher Verlag, 1992.

---. Society of Society. Bd. 1. Frankfurt am Main: Suhrkamp, 1997.

---. Cognition as Construction. Bern: Benteli, 1988.

---. Social Systems. Frankfurt am Main: Suhrkamp, 1984.

Luhmann, Niklas and Schorr, Karl-Eberhard. Between Beginning and End: Questions of Pedagogy. Frankfurt am Main: Suhrkamp, 1990.

Maffie, James. “Recent Work on Naturalized Epistemology.” American Philosophical Quarterly 27. 4 (1990): 281-93.

Maturana, Humberto and Varela, Francisco. “Autopoietic Systems: A Characterization of the Living Organization.” University of Illinois, Urbana IL, Biological Computer Lab Report 9.4 (1975): 187-96.

---. Tree of Cognition: Biological Roots of Human Cognition. Bern, München: Scherz, 1987.

Middleton, David and Edwards, Derek. Collective Remembering. London: Sage, 1990.

Pfarr, Jodi. Protophysics and Theory of Relativity. Mannheim: Bibliographisch Institut, 1981.

Piaget, Jean. Biology and Cognition. Frankfurt am Main: Suhrkamp, 1974.

---. The Construction of Reality in the Child. London: Routledge \& Regan Paul, 1978.

Piaget, Jean. The Principles of Genetic Epistemology. New York: Basic Books, 1972.

Quine, Willard van Orman. Ontological Relativity and Other Essays. New York, London: Columbia University Press, 1969.

Sarbin, Theodore R. and Kitsuse, John I. Constructing the Social. London: Sage, 1994.

Stekeler-Weithofer, Pirmin. "Introduction to Scientific and Theoretical Status of Prototheory." Ed. Eva Jelden. Prototheory_Practice and Cognition? Leipzig: Leipziger Universitätsverlag, 1995. 9-15.

Ulanovsky, Aleksey M. “Qualitative Research: Approaches, Strategies, Methods.” Psychological Journal 30. 2 (2009): 5-19.

Wallner, Friedrich G. Eight Lectures about Constructive Realism. Wein: WUV Universitätsverlag, 1990.

---. “Constructive Realism: Theory of New Paradigm?” Eds. Friedrich G. Wallner, Joseph Schimmer, and M. Costazza. Borders of Constructive Realism. Wein: WUV Universitätsverlag, 1993a. 12-21.

---. “Vienna’s New School of Constructive Realism.” Eds. Friedrich G. Wallner, Joseph Schimmer, and M. Costazza. Borders of Constructive Realism. Wein: WUV Universitätsverlag, 1993b. 22-35.

---. Reality Construction. Wein: Braumüller, 1992.

Wartofsky, Marx. "Epistemology Historicized.” Eds. Abner Shimony and Debra Nails. Naturalistic Epistemology. Dodrecht: Reidel, 1987. 357-74.

Watzlawick, Paul. The Invented Reality. München: Piper Verlag, 1981.

---. How Real Is Real? New York: Vintag Books, 1976. 